\title{
The Linkage Between State and National Output: A Case Study of Connecticut
}

\section{Francis W. Ahking and Maneechit Pattanapanchai*}

\begin{abstract}
We test for the short-run and long-run relationships between the Connecticut real gross state product and the U.S. real gross domestic product using quarterly data and a number of different statistical approaches. Quarterly observations on Connecticut real gross state product are not generally available to the public and the series is one of a few such series available. This presents a unique opportunity for such research. Our results show that these two series are not cointegrated for the full sample of 1969:1 to 1995:3, but are cointegrated for a shorter sample period from 1969:1 to 1988:4. For the period from 1969:1 to 1995:3, we find unidirectional causality from the U.S. real gross domestic product to the Connecticut real gross state product.
\end{abstract}

\section{INTRODUCTION}

It is well known among regional science economists that the national economy exerts an important exogenous influence on the state/regional economy. ${ }^{1}$ Although the empirical relationship between the state/regional economy and the national economy has a long history, we know of no formal theoretical model that exists to explain this relationship. Nevertheless, it is instructive to try to conceptualize this relationship if only to clarify the empirical relationship that may exist between them. One way is to view the state/regional economy as a "small" open economy on a fixed exchange rate standard, and the U.S. as the "rest of the world." These open economy models, however, are generally not concerned with the relationship between the economic growth of the "small" and the "rest of the world" economies. Alternatively, we can argue that, given that there is no barrier to mobility of labor, capital, and technological transfer among states and regions, the growth rates of the states and/or regions should converge. Since the national economy is the sum of the state economies, this argument suggests a positive relationship between the state/regional economy and the national economy. On the other hand, given a different natural resource endowment (e.g., climate and mineral deposits), the growth of a state/regional economy may be more dependent on the world's demand, which may not coincide with the growth of the U.S. economy. The above discussion suggests that the relationship between the state/regional economy and the national economy is an empirical question and

*Associate Professor and Graduate Student, respectively, Department of Economics, University of Connecticut, Storrs, CT. We wish to thank Professors William Lott, Dennis Heffley, Stephen Miller, Will McEachern, and Steve Cunningham for helpful discussions. We especially wish to thank Professor Lott for making the data on the Connecticut real gross state product available to us. The data can be obtained from the first-named author by request. We also wish to acknowledge the very helpful comments from a referee of this journal. All remaining errors are our responsibility.

1See for example, Anderson (1979), Dua and Ray (1995), and the studies cited in Dua and Ray (1995). 
that the empirical relationship is potentially different for different states and/or regions of the country.

We investigate the linkage between real output of the U.S. and Connecticut using a quarterly time series on Connecticut's real gross state product. Our study differs from most previous studies on the same topic in several respects. First', we use a much more comprehensive measure of a state's economic activities than do previous studies. ${ }^{2}$ The time series on Connecticut's real gross state product is not generally available to the public and is one of a few such series available. Furthermore, an advantage of focusing on only two time series is that it allows us to conduct more extensive empirical analysis than previous studies, which tend to use a large number of variables.

Second, recent advances in cointegration analysis have prompted several researchers to examine the short-run and long-run relationships between the national and state/regional variables (e.g., Shoesmith 1992, 1995; LeSage 1990; Schmidt 1995). The main focus of these studies was on the forecasting properties of cointegrated and noncointegrated variables. Our study, however, focuses on the statistical relationship between the state and national real outputs, and also on the robustness of our cointegration results. In sum, we study both the short-run relationship and the long-run relationship between Connecticut's real output and the real output of the U.S., and we believe that we are among the first to provide such an analysis using the time series on Connecticut's real gross state product. We are also interested in testing whether or not the U.S. real output is exogenous to the Connecticut real output. Thus, our study is very much in the same spirit as the recent empirical literature on growth economics, in which researchers are interested in whether or not the growth rates of the world economies converge over time.

Finally, the empirical findings of this paper should be of interest to state/regional policy makers. As pointed out by Smith (1996), information about the national economy is available more frequently and earlier than information about state/regional economic conditions (see also Footnote 3 below). Thus, if we find that the real output of the U.S. is a leading indicator of Connecticut's real output, this information can be used as an advanced signal of the health of the Connecticut economy.

We use a number of empirical methodologies in this study. We start by examining the stochastic properties of the individual time series of output. We next use the cointegration analyses of Johansen (1988) to examine whether or not the two time series of real output have a stable long-run equilibrium relationship. Finally, we model the two time series of output as either an error-correction model (ECM) or a vector-autoregressive (VAR) model to examine the short-run linkage between the two real output time series and to determine their causal relationship.

2 The state-level variables typically used by previous studies include the unemployment rate, nonagricultural employment, real personal income, and housing permits authorized, or measures of output at the industry level of the state. See, for example, the studies by Dua and Ray (1995), Shoesmith (1992, 1995), Schmidt (1995), and LeSage (1990). 
The remainder of the paper is in two sections. In Section 2, we discuss our data set and the empirical methodologies and present our empirical results. We give our summary and conclusions in Section 3.

\section{DATA AND EMPIRICAL RESULTS}

The two time series used in this study are the quarterly Connecticut real gross state product (RGSP), measuring the real output of Connecticut, and the quarterly real gross domestic product (RGDP) of the U.S., measuring the real output of the U.S. Quarterly Connecticut RGSP data are the most comprehensive measure of Connecticut's economic activities, but they are not generally available to the public. They are constructed and provided to us by Professor William Lott, Associate Director of the Center for Economic Analysis, University of Connecticut. ${ }^{3}$ Quarterly Connecticut RGSP data are constructed following the methodology in Berger and Phillips (1995), and are seasonally adjusted and expressed in millions of constant 1987 dollars. Quarterly U.S. RGDP data are also seasonally adjusted, are expressed in billions of constant 1987 dollars, and are obtained from a CD-ROM of OECD data. Our sample period starts in the first quarter of 1969 (1969:1) and ends in the third quarter of 1995 (1995:3). ${ }^{4}$ Both data series are transformed by taking the natural logarithm of the original series. This reduces heteroskedasticity in the data and allows us to interpret the first difference as approximately the percentage rate of change.

Table 1 presents some descriptive statistics comparing U.S. and Connecticut recessions since 1969. Since 1969, there had been five U.S. recessions totaling 57 months, each one lasting an average of 11.4 months, compared to four recessions in Connecticut totaling 101 months, each one lasting an average of 25.25 months. Thus, Connecticut had about twice the number of months in recession compared to the U.S., much of which came from the last two Connecticut recessions. The first recessions for the U.S. and Connecticut since 1969 occurred almost contemporaneously. The second U.S. recession led Connecticut's second recession by about six months. After this, however, recessions in the U.S. and Connecticut were dramatically different. While the U.S. had three more recessions totaling 30 months, Connecticut had two lengthy recessions totaling 74 months. Thus, recessions in the U.S. and Connecticut appear to be similar at the beginning of the sample period, but take on rather different characteristics in the 1980s.

We now turn to our formal statistical analysis by examining the stochastic properties of the individual time series. Table 2 reports the autocorrelation

\footnotetext{
${ }^{3}$ The Bureau of Economic Analysis of the U.S. Department of Commerce does publish, with a lag of several years, annual series of nominal and real gross state product for all 50 states. The quarterly Connecticut RGSP series is constructed to be consistent with the annual series.

4The Connecticut RGSP data are available to 1996:2. There is however, a base year change for the U.S. RGSP data from constant 1987 to constant 1992 dollars starting in 1995:4, and we are unable to obtain a consistent time series of the U.S. RGDP in constant 1992 dollars going back to 1969:1, the first observation that we have for the Connecticut RGSP data. It should also be noted that the Connecticut RGSP averages about 1.6 percent of the U.S. RGDP over the entire sample period. Since we consider this to be a relatively small percentage, we have not attempted to purge the Connecticut RGSP from the U.S. RGDP series. Another reason for not doing so is that since the two series are independently calculated, it is not clear how best to purge the Connecticut RGSP from the U.S. RGDP without introducing significant measurement errors into the U.S. RGDP time series.
} 
functions of the two time series. Columns 2 and 4 show the autocorrelations of the level of the Connecticut RGSP and the U.S. RGDP, respectively. Both series show the characteristics of a nonstationary time series. First, the autocorrelation functions of both series damp out very slowly, and the autocorrelation coefficient at the first lag is very close to unity in both cases. In fact, the standard error of the autocorrelation coefficient at the first lag is 0.097 , calculated as $1 / \mathrm{n}^{1 / 2}$, where $n=107$ (the number of observations). Thus, the autocorrelation coefficient at the first lag is not statistically different from unity at the $5 \%$ significance level for both series.

\section{TABLE 1}

Business Cycle Reference Dates

\begin{tabular}{llc}
\hline & \multicolumn{1}{c}{ U.S. } & \\
\hline Peak & \multicolumn{1}{c}{ Trough } & $\begin{array}{c}\text { Duration in Months } \\
\text { For Contraction }\end{array}$ \\
\hline December 1969 & November 1970 & 11 \\
November 1973 & March 1975 & 16 \\
January 1980 & July 1980 & 6 \\
July 1981 & November 1982 & 16 \\
July 1990 & March 1991 & 8 \\
\hline & Total $~$ & 57 \\
& Average Per Contraction & 11.4 \\
\hline
\end{tabular}

Connecticut

\begin{tabular}{llc}
\hline Peak & \multicolumn{1}{c}{ Trough } & $\begin{array}{c}\text { Duration in Months } \\
\text { For Contraction }\end{array}$ \\
\hline December 1969 & October 1970 & 10 \\
May 1974 & September 1975 & 17 \\
March 1980 & January 1983 & 34 \\
February 1989 & June 1992 & 40 \\
\hline & Total & 101 \\
& Average Per Contraction & 25.25 \\
\hline
\end{tabular}

Notes: The U.S. business cycle reference dates are taken from the NBER's web site at http://www.nber.org/cycles.html

The Connecticut busines cycle reference dates are taken from The Connecticut Economic Digest, June 1997. The methodology for dating the Connecticut cycles is developed by Dua and Miller (1996).

Columns 3 and 5 of Table 2 show the first difference of the respective series. Here, we make a couple of observations. First, both series appear to be stationary after first-differencing. Second, even though both series are seasonally adjusted, there appears to be residual seasonality. For example, the autocorrelation coefficients at lag 4 are statistically different from zero for the Connecticut RGSP, and the autocorrelation coefficients at the other seasonal lags of 8,16 , and 20 are large compared to the autocorrelation coefficients of the surrounding lags. Similarly, for the U.S. RGDP, the autocorrelation coefficients are statistically different from zero at the seasonal lags of 8 and 12.

At the bottom of Columns 3 and 5 we also show the standard error of the series as a rough measure of the volatility of the series. It can be seen that the firstdifferenced Connecticut RGSP series is about 23 percent more volatile than the 
first-differenced U.S. RGDP series for the entire sample period. When the sample period is divided into two subperiods, however, we see that the volatility is about the same for the period 1969:1-1988:4 for both series. ${ }^{5}$ The subperiod 1989:11995:3, however, is rather different for both series. For the U.S., the first-differenced series is only half as volatile as the earlier sample period, but the first-differenced Connecticut series is about 30 percent more volatile than the earlier sample period and about 160 percent more volatile than the first-differenced U.S. series for the same period. Thus, starting in the late 1980s, the Connecticut RGSP series appears to be more volatile both relative to the U.S. series and to its own past.

TABLE 2

Autocorrelation Functions

\begin{tabular}{|c|c|c|c|c|}
\hline \multirow[b]{2}{*}{ Lag } & \multicolumn{2}{|c|}{ Connecticut RGSP } & \multicolumn{2}{|c|}{ U.S. RGDP } \\
\hline & Level & First Difference & Level & First Difference \\
\hline 1 & 0.98 & 0.27 & 0.97 & 0.29 \\
\hline 2 & 0.96 & 0.20 & 0.94 & 0.18 \\
\hline 3 & 0.94 & 0.11 & 0.91 & 0.05 \\
\hline 4 & 0.92 & 0.44 & 0.88 & 0.05 \\
\hline 5 & 0.89 & 0.01 & 0.85 & -0.04 \\
\hline 6 & 0.87 & -0.04 & 0.82 & -0.02 \\
\hline 7 & 0.85 & -0.07 & 0.79 & -0.11 \\
\hline 8 & 0.82 & 0.18 & 0.76 & -0.31 \\
\hline 9 & 0.80 & -0.13 & 0.73 & -0.12 \\
\hline 10 & 0.77 & -0.10 & 0.70 & -0.02 \\
\hline 11 & 0.75 & -0.18 & 0.67 & -0.01 \\
\hline 12 & 0.72 & 0.13 & 0.64 & -0.28 \\
\hline 13 & 0.70 & -0.11 & 0.62 & -0.15 \\
\hline 14 & 0.67 & -0.03 & 0.59 & -0.20 \\
\hline 15 & 0.65 & -0.04 & 0.57 & -0.13 \\
\hline 16 & 0.62 & 0.14 & 0.55 & -0.04 \\
\hline 17 & 0.60 & -0.06 & 0.53 & -0.03 \\
\hline 18 & 0.57 & -0.06 & 0.51 & 0.01 \\
\hline 19 & 0.55 & 0.01 & 0.48 & 0.00 \\
\hline 20 & 0.52 & 0.16 & 0.46 & 0.12 \\
\hline 21 & 0.49 & -0.10 & 0.44 & 0.15 \\
\hline 22 & 0.47 & -0.04 & 0.41 & 0.06 \\
\hline 23 & 0.44 & -0.06 & 0.39 & -0.04 \\
\hline 24 & 0.40 & 0.02 & 0.36 & -0.03 \\
\hline S.E. & $(1969: 1-1995: 3)$ & 0.011 & & 0.009 \\
\hline S.E. & $(1969: 1-1988: 4)$ & 0.010 & & 0.010 \\
\hline S.E. & (1989:1-1995:3) & 0.013 & & 0.005 \\
\hline
\end{tabular}

Table 3 shows the cross-correlation function of the growth rates. The table shows that the series are strongly contemporaneously correlated, but no clear lead-lag relationship emerges. For example, we find statistically significant coefficients at leads 1, 2, 3, and 4, but also at lag 1.6 In sum, the analyses in this section show that both time series are nonstationary, but do not reveal any clear relationship between the two series other than that they are strongly contemporaneously correlated.

${ }^{5}$ The split at 1988:4 is somewhat arbitrary. It is chosen so that the first sample period will end before the beginning of Connecticut's last recession. Also, 1988:4 corresponds roughly to the beginning of a volatile period in Connecticut.

${ }^{6}$ We suspect that the statistically significant coefficients at lead 8 and lag 8 are either spurious or are the results of the residual seasonality in the series. 
TABLE 3

Cross-Correlation Function

\begin{tabular}{lcccccc}
\hline Lags: & -12 & -11 & -10 & -9 & -8 & -7 \\
& -0.14 & -0.17 & -0.10 & -0.07 & $-0.21^{*}$ & -0.16 \\
Lags: & -6 & -5 & -4 & -3 & -2 & -1 \\
& 0.03 & 0.05 & $0.21^{*}$ & $0.20^{*}$ & $0.32^{*}$ & $0.26^{*}$ \\
Lags: & 0 & 1 & 2 & 3 & 4 & 5 \\
& $0.47^{*}$ & $0.29^{*}$ & 0.09 & 0.00 & 0.07 & 0.02 \\
Lags: & 6 & 7 & 8 & 9 & 10 & 11 \\
& -0.04 & -0.11 & $-0.24^{*}$ & -0.14 & -0.08 & -0.08 \\
\hline
\end{tabular}

Note: *denotes significantly different from zero at the $5 \%$ level.

We next use Johansen's (1988) multivariate maximum likelihood approach to cointegration to examine the long-run relationship between the Connecticut RGSP and the U.S. RGDP. Preliminary data analysis using the Kwiatkowski et al. (1992) test for trend stationarity (i.e., the time series is stationary after detrending with a deterministic time trend) and the augmented Dickey-Fuller (1981) test, together with the results of Table 2, lead us to conclude that both the U.S. RGDP and the Connecticut RGSP time series can be characterized as integrated processes of order one, i.e., I(1) processes. ${ }^{7}$ The upper panel of Table 4 reports the lambdamax and the trace test statistics on the number of cointegrating vector using a lag length of five for the cointegration model. The results are rather robust with respect to different lag lengths, however. The lag length of five is chosen for reporting here because it gives the best diagnostic statistics in terms of serial correlations in the residuals and normality of the residuals. Both the lambda-max and the trace test statistics have been adjusted for finite sample bias as suggested in Cheung and Lai (1993). We see that the lambda-max statistics show that we can reject the null hypothesis of no cointegrating vector in favor of the alternative hypothesis of one cointegrating vector at the $90 \%$ confidence level, but not at the $95 \%$ level. On the other hand, using the trace statistics, we cannot reject the hypothesis of no cointegrating vector at both the $90 \%$ and $95 \%$ confidence levels. Taken together, the evidence in favor of cointegration appears to be weak. Thus, we conclude that there is no stable long-run relationship between the Connecticut RGSP and the U.S. RGDP.

Since there appears to be a structural break in the time series of both the variables around 1988:4, we decide to check the robustness of our cointegration results by repeating the test but dropping the sample period 1989:1-1995:3.8 We report our results in the lower panel of Table 4 . This time, the results are rather different. The lambda-max statistics show that the null hypothesis of no cointegrating vector can be rejected at the $90 \%$ confidence level, but not at the $95 \%$ level. The trace statistics, however, show that the hypothesis of no cointegrating vector can be rejected at both the $90 \%$ and $95 \%$ confidence levels, in favor of one cointegrating vector. Thus, we find much stronger evidence of cointegration in this shorter

\footnotetext{
${ }^{7}$ These results are available from the authors.

${ }^{8}$ This structural break corresponds roughly to the U.S. recession starting in July 1990 and the Connecticut recession starting in February 1989. The cause of the U.S. recession is yet unknown. The recession in Connecticut is widely attributed to the collapse of the real estate market in Connecticut and the cutback in defense spending, which affected the defense industries in Connecticut.
} 
sample period. Furthermore, the hypothesis that the U.S. RGDP is weakly exogenous in the long run is not rejected at the $10 \%$ and $5 \%$ significance levels with a $\chi^{2}(1)$ statistic of 2.20 .

\section{TABLE 4}

Lambda-Max and Trace Statistics

Full sample: 1969:1-1995:3

\begin{tabular}{lcrrrrr}
\hline & \multirow{2}{*}{ Lambda-Max } & Test Statistics & \multicolumn{3}{c}{ Critical Values } \\
& & Trace & \multicolumn{2}{c}{ Lambda-Max } & $90 \%$ & $95 \%$ \\
\hline 0 & $12.37^{* *}$ & & $90 \%$ & $95 \%$ & $90 \%$ \\
1 & 2.36 & 14.73 & 10.29 & 14.90 & 15.66 & 17.95 \\
& 2.36 & 7.50 & 8.18 & 6.50 & 8.18 \\
\hline
\end{tabular}

Short Sample: 1969:1-1988:4

\begin{tabular}{rcccrrr}
\hline & \multirow{2}{*}{ Test Statistics } & \multicolumn{4}{c}{ Critical Values } \\
& Lambda-Max & Trace & \multicolumn{2}{c}{ Lambda-Max } & \multicolumn{2}{c}{ Trace } \\
& & & $90 \%$ & $95 \%$ & $90 \%$ & $95 \%$ \\
\hline 0 & $12.59^{* *}$ & $19.00^{* *}$ & 10.29 & 14.90 & 15.66 & 17.95 \\
1 & 6.42 & 6.42 & 7.50 & 8.18 & 6.50 & 8.18 \\
\hline
\end{tabular}

Notes: The critical values for the Trace statistics at the $90 \%$ and $95 \%$ confidence levels are taken from Osterwald-Lenum (1992).

$r$ is the number of cointegrating rank or vector.

$*$ ** denotes that the null hypothesis of no integration can be rejected at the $95 \%$ and $90 \%$ confidence intervals respectively.

The finding that the Connecticut RGSP and the U.S. RGDP are not cointegrated for 1969:1-1995:3 does not preclude them from having a short-run relationship. In our final statistical test, we model the two variables as a VAR system, i.e., where $a$ and $b$ are constants, Dys $s_{t}$ and Dyd $d_{t}$ are the first difference of the natural

$$
\text { Dys }_{\mathrm{t}}=\mathrm{a}+\sum_{\mathrm{i}=1}^{\mathrm{m}_{1}} \gamma_{\mathrm{i}} \text { Dys }_{\mathrm{t}-\mathrm{i}}+\sum_{\mathrm{i}=1}^{\mathrm{n}_{1}} \delta_{\mathrm{i}} \operatorname{Dyd}_{\mathrm{t}-\mathrm{i}}+\zeta_{\mathrm{t}}
$$

and

$$
\operatorname{Dyd}_{\mathrm{t}}=\mathrm{b}+\sum_{\mathrm{i}=1}^{\mathrm{m}_{2}} \varphi_{\mathrm{i}} \text { Dys }_{\mathrm{t}-\mathrm{i}}+\sum_{\mathrm{i}=1}^{\mathrm{n}_{2}} \tau_{\mathrm{i}} \operatorname{Dyd}_{\mathrm{t}-\mathrm{i}}+\xi_{\mathrm{t}}
$$

logarithm of the Connecticut RGSP and the U.S. RGDP, respectively, and $\zeta_{t}$ and $\xi_{t}$ are serially uncorrelated error processes. The autoregressive lag lengths of the two variables $\left(m_{1}, m_{2}\right.$ for the Connecticut RGSP and $n_{1}, n_{2}$ for the U.S. RGDP) are determined using the procedure discussed in Hsiao (1981) using a maximum lag length of 12.

The VAR is a particularly useful model for the problem at hand. The distributed lags capture the short-run dynamic between the two variables and standard Granger causality tests can be conducted to determine the causal ordering of the two variables. We estimate Equations 1 and 2 as a system using the method of iterative seemingly unrelated regressions to take account of the strong contemporaneous correlation between the two variables (see Table 3 ). After determining the optimal lag lengths for Equations 1 and 2 (they are: $\mathrm{m}_{1}=5, \mathrm{~m}_{2}=1, \mathrm{n}_{1}=2$, and $\mathrm{n}_{2}=12$ ), we perform Granger causality tests to determine the causal ordering of 
the two variables. Since we are interested in the significance of the various variables and not in the estimated coefficients of these variables (which are difficult to interpret), we only report the $\chi^{2}$ statistics for the significance tests in Table 5.9

TABLE 5

Chi-Squared Statistics

\begin{tabular}{cl}
\hline Hypothesis tested & $\chi^{2}$ (d.f.) \\
\hline$\delta_{1}=\delta_{2}=0$ & $8.78^{*}(2)$ \\
$\varphi_{1}=0$ & $1.25(1)$ \\
\hline
\end{tabular}

Note: *denotes significantly differenct from zero at the $5 \%$ level.

d.f. denotes degress of freedom.

The top row of Table 5 shows that we can reject at the $5 \%$ significance level the hypothesis that the U.S. RGDP does not Granger cause the Connecticut RGSP. From the bottom row of Table 5, we see that the hypothesis that the Connecticut RGSP does not Granger cause the U.S. RGDP is not rejected at the 5\% significance level. The VAR results suggest that for 1969:1-1995:3, the Connecticut RGSP and the U.S. RGDP are related in the short run, with unidirectional causal ordering from the U.S. RGDP to the Connecticut RGSP.

\section{SUMMARY AND CONCLUSION}

We test for the short-run and long-run relationships between the Connecticut RGSP and the U.S. RGDP using quarterly data. As quarterly Connecticut RGSP data are not generally available to the public, this presents a unique opportunity for such an investigation. Using several statistical techniques, we find that there is no evidence of a long-run equilibrium relationship between the Connecticut RDSP and the U.S. RGDP for 1969:1-1995:3. They are, however, related in the short run, with unidirectional causal ordering from the U.S. RGDP to the Connecticut RGSP. This means that economic growth in Connecticut is very much dependent on the growth of the national economy in the short run. On the other hand, the dependence of Connecticut's economy on the national economy means that information about the national economy contains valuable information about the future course of the Connecticut economy. This is particularly useful to the policy makers who frequently have to make decisions based on the outlook for the state, since the information about the national economy is typically available more frequently and in a more timely manner than the information about the state economy. More generally, since state real output is the most comprehensive measure of the activity of a state and since the time series on the state real output can be constructed relatively inexpensively using publicly available information, we strongly recommend that more state policy makers seriously consider the costs and benefits of constructing such a time series for their states.

Our results also indicate that the Connecticut RGSP and the U.S. RGDP are cointegrated for the shorter sample period of 1969:1-1988:4. The obvious explanation of this result is that the structural changes that occurred in the Connecticut and U.S. economies around 1989 have made it difficult to uncover any long-run

\footnotetext{
${ }^{9}$ The sum of the coefficients of the casual variables are positive in both cases, however as expected.
} 
equilibrium relationship between the two time series, although a stable long-run equilibrium relationship existed before 1989. Unfortunately, whether or not the long-run equilibrium relationship will be reestablished in the future between the two time series is something we cannot predict at the moment.

\section{REFERENCES}

Anderson, Paul A. "Help for the Regional Economic Forecaster: Vector Autoregression." Federal Reserve Bank of Minneapolis Quarterly Review (Summer 1979), 2-7.

Berger, Franklin D., and Keith R. Phillips. "A New Quarterly Output Measure For Texas." Federal Reserve Bank of Dallas Economic Review (1995), 16-23.

Cheung, Yin-Wong, and Kon S. Lai. "Finite-Sample Sizes of Johansen's Likelihood Ratio Tests for Cointegration." Oxford Bulletin of Economics and Statistics 55 (1993), 313-328.

Dickey, David A., and Wayne A. Fuller. "Likelihood Ratio Statistics for Autoregressive Time Series with a Unit Root." Econometrica 49 (July 1981), 10571072.

Dua, Pami, and Stephen M. Miller. "Forecasting and Analyzing Economic Activity with Coincident and Leading Indexes: The Case of Connecticut." Journal of Forecasting 15 (1996), 509-526.

Dua, Pami, and Subhash Ray. "A BVAR Model for the Connecticut Economy." Journal of Forecasting 14 (1995), 167-180.

Hsiao, Cheng. "Autoregressive Modelling and Money-Income Causality Detection." Journal of Monetary Economics 7 (1981), 85-106.

Johansen, Soren. "Statistical Analysis of Cointegration Vectors." Journal of Economic Dynamics and Control 12 (1988), 231-254.

Kwiatkowski, Dennis, Peter C.B. Phillips, Peter Schmidt, and Yongcheol Shin. "Testing the Null Hypothesis of Stationarity Against the Alternative of a Unit Root." Journal of Econometrics 54 (1992), 159-178.

LeSage James P. "Forecasting Metropolitan Employment Using An Export-Based Error-Correction Model." Journal of Regional Science 30 (1990), 307-323.

Osterwald-Lenum, M. "A Note with Fractiles of the Asymptotic Distribution of the Maximum Likelihood Cointegration Rank Test Statistics: Four Cases." Oxford Bulletin of Economics and Statistics 54 (1992), 461-472.

Schmidt, James R. "Stochastic and Deterministic Trends in State Economies." Growth and Change 26 (Winter 1995), 59-75.

Shoesmith, Gary L. "Non-Cointegration and Causality: Implications for VAR Modeling." International Journal of Forecasting 8 (1992), 187-199.

"Long-Term Forecasting of Noncointegrated and Cointegrated Regional and National Models." Journal of Regional Science 35 (1995), 43-64.

Smith, Tim R. "The Relationship between the Tenth District Economy and the National Economy." Federal Reserve Bank of Kansas City Economic Review 81 (Fourth Quarter 1996), 77-90. 
